\title{
Strategic sense-giving at the micro-level: facilitating and triggering coordinated action
}

\author{
Timo Vuori \\ Department of Industrial Engineering and Management, \\ Aalto University, \\ P.O. Box 15500, 00076 Aalto, Finland \\ E-mail: timo.vuori@tkk.fi
}

\begin{abstract}
Collective, coordinated action allows a group to achieve results that are beyond the sum of individual efforts. How do executives help people to take coordinated actions? How do they influence the sense-making of the people to ensure that the group is able to act as a collective? To answer these questions, I carried out an in-depth study of a CIO's sense-giving tactics and identified how his sense-giving facilitates and triggers collective, coordinated action. Accordingly, this sense-giver creates both shared understanding and shared faith through specific micro-tactics, to increase 'collective action potential', which he then transforms to action by using specific triggering tactics. I abstract the sense-giving tactics used by the CIO and explain their theoretical mechanisms. Thus, I extend research on sense-giving and coordinated action.
\end{abstract}

Keywords: sense-giving; sense-making; coordination; strategy implementation.

Reference to this paper should be made as follows: Vuori, T. (2011) 'Strategic sense-giving at the micro-level: facilitating and triggering coordinated action', Int. J. Management Development, Vol. 1, No. 1, pp.1-14.

Biographical notes: Timo Vuori is interested in the psychological antecedents of high performance. He has presented several papers on the topic at the Academy of Management and Strategic Management Society conferences. He will defend his doctoral theses during Spring/Summer 2011. Practice-wise, his interest was triggered in the context of ice-hockey coaching about ten years ago and has now evolved to consider high performance of business teams.

\section{Introduction}

Strategy implementation is often about making people take novel, coordinated action. It is insufficient that the (top) members of an organisation have an idea for a new strategy; the organisational members need to take collective, coordinated action that shapes and makes the strategy. This importance of implementation, and the lack of research thereof, has recently been brought up by both strategy process (e.g., Hutzschenreuter and Kleindienst, 2006) and strategy-as-practice (e.g., Jarzabkowski, 2008; Johnson et al., 2003) scholars.

Research on sense-making and sense-giving provides a useful theoretical starting point for understanding coordinated action as a part of strategy process and practice. It 
has been suggested that to be able to act as a collective group (Hargadon and Bechky, 2006; Weick, 1993), people need to relate to one another (Weick and Roberts, 1993) in a way that allows mutual prediction of each other's actions [Weick, (1979), ch.4]. This means that they need to have compatible understanding of the situation in which they are acting. In addition, people need to have faith in their actions (Weick, 2006) and trust each other (Dirks and Ferrin, 2001; Quinn and Worline, 2008), as the level of effort depends on a belief that effort leads to success. Once these conditions are met, people are likely to take coordinated action and shape the evolving situation (Weick, 1995) (i.e., shape and make the strategy).

Collective action is often difficult to maintain and establish, however (e.g., Weick, 1993). Balogun and Johnson, for example, recognised how middle managers' sense-making diverged during an organisational restructuring (Balogun and Johnson, 2004), resulting in unintended difficulties (Balogun and Johnson, 2005). Maitlis (2005) found that a series of consistent actions only emerged when multiple parties were part of the sense-making process and that wide participation depended on perceptions of need and resources (Maitlis and Lawrence, 2007). It has also been recognised that the sense-giving processes can become framing contests between different managers, where the one who is able to impose his or her frame to others will have the biggest influence on decision-making (Kaplan, 2008).

Managers and executives use various sense-giving (Gioia and Chittipeddi, 1991) tactics during framing contests. The tactics include inspiring metaphors (Hill and Levenhagen, 1995), adapting explanation style and displayed emotions (Rouleau, 2005); using specific framing language (Fiss and Zajac, 2006), economic justifications for social issues (Sonenshein, 2006), sense-breaking (Pratt, 2000), narratives (Brown et al., 2008; Dunford and Jones, 2000; Steuer and Wood, 2008), and crediting (Foldy et al., 2008) or discrediting (Kaplan, 2008) constituents. However, these scholars have not linked their investigation and theorisation of the sense-giving tactics back to the idea of coordinated action. How do sense-giving tactics facilitate coordinated action? Why is a certain way of framing necessary for coordinated action? What triggers coordinated action once people start framing issues similarly?

I start filling in the above identified gap by developing an empirically grounded model of action facilitating and triggering sense-giving. Accordingly, a sense-giver first creates potential for coordinated action by making people frame the situation in adequately similar ways and by making people believe that the possible coordinated action will result in positive outcomes. Once there is enough compatible understanding and mutual faith, the sense-giver can then trigger specific coordinated actions that help to shape and make the new strategy.

This model highlights two important themes for strategic sense-giving. The first is that common understanding and faith in the strategy should not be goals per se but that sense-givers should instead appreciate the instrumental value of these, in the process of making people take coordinated action. The second key insight comes from the word coordinated, in coordinated action. People need to be able to work together and take actions that are mutually reinforcing. This means that their trust and faith in each other matters in the process. 


\section{Theoretical background}

\subsection{Coordinated action}

When different individuals act, they produce some outcomes that may or may not be compatible and mutually reinforcing. Coordinating actions refers to activities that ensure that the actions of each individual are in line and thus ensures that the collective actions and outputs are better. In simple tasks, such as producing similar technological components, coordination can be relatively simple and achieved by technical specifications and simple rules. (e.g., Thompson, 1967) However, in more complex situations, where there are many interdependencies between different individual actions and the situation may require dynamic adaptation, coordination becomes more difficult (e.g., Gode-Sanchez, 2009; Rico et al., 2008; Weick, 1993). ${ }^{1}$

At the same time, as coordination is more difficult in more complex and dynamic situations, the benefits of successful coordination are also higher. A collective of people that can take mutually reinforcing actions can handle complexity that is beyond any single individual's comprehension (e.g., Spender, 1996; Weick, 1979; Weick and Roberts, 1993). Thus, the collective is able to do things that have superior value, which may then be rewarded generously.

\subsection{Necessary conditions for coordinated action}

The idea of an adaptive collective has triggered many researchers to investigate the necessary conditions for successful coordinated action. I will discuss this research in two parts. First, I will discuss how shared understanding between people, whether explicit or implicit, helps people to know what to do and how they should do it and thus improves coordination. Second, I will turn to the more affective side of coordinated action and discuss how faith in action and trust in other members ensures that effort is put into the action, thus facilitating the achievement of collective, coordinated action.

\subsubsection{Shared understanding}

Shared understanding consists of two elements. First, people need to roughly know, explicitly or implicitly, what they are trying to achieve as a collective (Senge, 1990). This ensures that each individual can roughly deduce what he or she should do to support the collective outcome and can anticipate what others are doing. Furthermore, by fixing the ends, people can save their limited cognitive resources for discussing the means and thus further ensure the smooth flow of actions (cf. March and Simon, 1958/1993).

Secondly, it helps if people understand what others are doing and how they are likely to react in evolving situations. They may not need to know the details of each subprocess, but they still need to roughly know how different individuals are likely to react to different contingencies (e.g., Huber and Lewis, 2010; Montague, 2006). When they do know, they can adjust their behaviour accordingly, without having to communicate all the details and reasons with others (this reduction in communication can save time and resources). In addition to being able to predict how others will behave, this knowledge of what others know and how they think can help in locating knowledge needed in some specific situations (Faraj and Sproull, 2000). 


\subsubsection{Trust and faith}

The claim that shared understanding leads to coordinated action, as discussed above, is based on the information processing paradigm: when people know what is going on and how everyone is doing their parts, they can coordinate their actions and achieve superior outcomes (cf. March and Simon, 1958/1993). The only problems that can arise, according to this view, relate to issues of not understanding what one should do and how one should do it and what others should do and how they should do it. However, a second aspect of coordinated action relates to the word action, as people need not only know what to do, but they also must $d o$, and the quality of this doing is dependent on the level of effort they put into the doing.

The level of effort put into action largely depends on a belief that effort leads to success (Weick, 2006; Vroom, 1964). When people believe that they are able to achieve a valuable outcome or goal, they will put in effort, whereas if they do not believe, they will not put in much effort. Thus, faith in the action itself is an important aspect of acting, and by extension, coordinated action [see Weick (2006) for a thorough discussion about faith]. It is consequently not enough that people know what to do and how they should do it, but they also must believe that they are able to do whatever they are supposed to do and that this action will lead to valuable outcomes.

Secondly, when we are talking about collective, coordinated action, it is not only an individual's belief in his or her abilities and in the goodness of the goal that influences his or her level of effort. Instead, because the outcome is achieved only if everyone in the group is able to do their part, an individual's level of effort will also depend on his or her belief that the other members of the group will do their parts successfully. Thus, the individual has to trust the other members of the acting group [see, e.g., Dirks and Ferrin (2001) on research on trust in organisations].

\subsection{Creating optimal initial conditions for coordinated action}

I have now discussed the necessary conditions of successful coordinated action, without paying much attention to the question of how. In this section, I address this question from the perspective of managers and discuss what we know about how managers can create these optimal conditions for groups that are about to start acting as a collective.

The basic idea in sense-making is that people take action, extract cues, interpret these cues and then take more actions and enact their understanding to their environment (Weick, 1995). Thus, the interpretation can become self-fulfilling, as the other actors in the situation tend to react to the first person's action (Weick, 1979). For example, if I interpret your neutral words as hostile, I may reply in a hostile way, to which you would again react in a hostile way. Thus, my interpretation becomes reality because of my own actions. In a similar way, if a person thinks that others are cooperative, he or she may act in ways that reinforce this belief and thus make an acting group more cooperative.

The interpretation of the cues is always influenced by the interpreter's mental model and identity (but the cues also influence the mental models and identity) (Gioia and Thomas, 1996; Nag et al., 2007; Weick, 1988, 1995). Thus, it can be argued that influencing these mental models and identities before the actual acting starts to take place can have crucial effects for the success of coordinated action. There is also ample 
empirical support from various settings that interpretations can become self-fulfilling and influence the actual doing of things (e.g., Doz, 1996; Livingston, 2003/1969; Tierney and Farmer, 2004).

Research on sense-giving has investigated the various ways people try to influence the sense-making of others (Gioia and Chittipeddi, 1991). In general, all studies revolve around the idea of showing some kinds of cues to others, while hiding other cues, as cues are the fuel of sense-making (Weick et al., 2005). Specific tactics recognised include using specific emotional tone (Rouleau, 2005), narratives (Boudes and Laroche, 2009; Brown et al., 2008), metaphors (Hill and Levenhagen, 1995), crediting constituents (Foldy et al., 2008), and emphasising some justifications over others (Sonenshein, 2006).

Some studies have also created models that describe how some outcome state can be achieved in several stages. For example, Pratt (2000) discussed the creation of strong organisational identification. First, the potential members' current identities should be broken by sense-breaking tactics, such as dream building that makes people realise the inadequacies of their present situation. This makes people more open to new influences, and sense-givers can then use tactics like positive programming and creation of cohesive small groups to make the people identify with the organisation. My goal in this study is to create a similar sense-giving model for facilitating and triggering coordinated action.

\section{Data and method}

The overall methodological approach of this study is qualitative theory elaboration (Lee et al., 1999), where data provides inspiration and reality checks for conceptual theory development (Siggelkow, 2007; Vuori, 2009). I started with the general theoretical framework of sense-making and sense-giving when I entered the field. As I collected and analysed the data, my focus moved towards coordinated action as the key outcome of sense-making and sense-giving.

\subsection{Research site and data collection}

I carried out about 100 days of observation in a large European company that provides manual and technological services for both firms and individuals. During this time, I carried out 19 interviews, had hundreds of informal discussions, and went through a large number of company documents and presentations. This long stay at the organisation provided me with a good contextual understanding of the issues discussed in the organisation as well as the different styles and cognition of different people.

My key focus evolved to be on the CIO of the company, and the sense-giving model built in this paper is based on a microscopic focus on the CIO's sense-giving tactics in seven separate meetings. However, it should be noted that the extended observation and informal discussions provided important inputs for the analysis of these seven meetings (cf. Rosen, 1988).

I was a silent observer in the seven meetings and made detailed, near verbatim notes of the meetings ( 55 hand-written pages). In addition, I interviewed three participants of the meetings, who worked near the CIO, and had several discussions with the CIO about the meetings as well as about his sense-giving tactics in general. 


\subsection{Data analysis and model development}

I started the data analysis by reading my field-notes and writing codes next to the sentences in the notes [Strauss and Corbin, (1998), ch.8]. These codes varied from short ones, such as 'accepts', to longer ones, such as 'starts to describe a goal but interrupts himself and goes back to the history and present'. It should be noted that my coding was informed by the general principles of sense-making and sense-giving at this phase of the analysis, as my goal was theory elaboration.

After I had coded each sentence/paragraph in my field notes and interview transcripts, I moved on to recognise more abstract categories in the data [Strauss and Corbin, (1998), ch.9]. I grouped similar codes together, started calling these groups categories, and named each category. I also combined some of the categories to form more categories at even higher levels of abstraction. The hierarchical structure that emerged is presented in Figure 1. Three key categories that ultimately emerged, after tens of iterations, are 'building understanding', 'building faith', and 'triggering coordinated action'.

Figure 1 Coding and categorisation

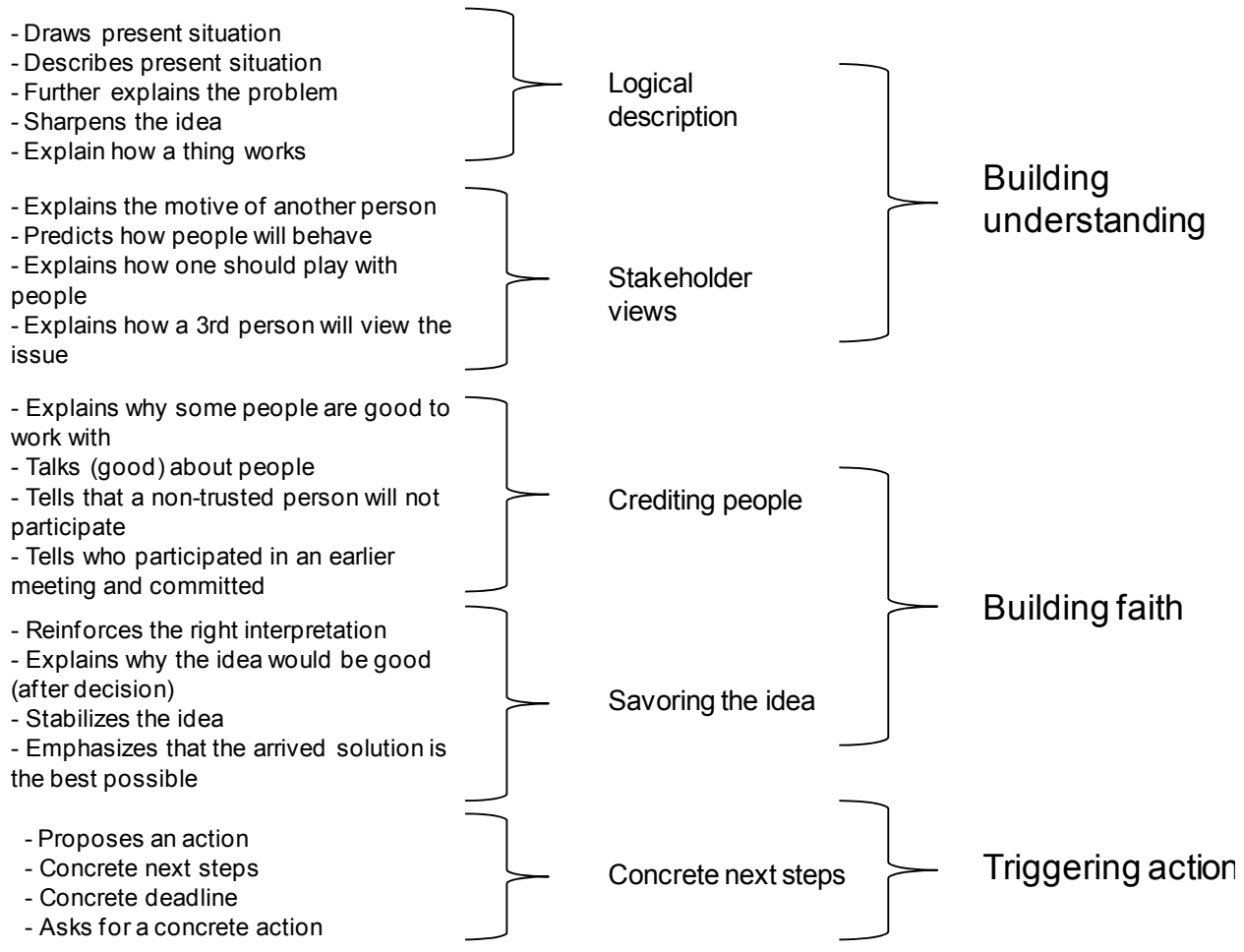

Once I had coded about ten pages of the field notes, I started writing memos and drawing diagrams to develop my theoretical ideas [Strauss and Corbin, (1998), ch.14]. I kept writing and drawing these until the end of the research process. Thus, the memos both helped me to focus my open coding and model development and were influenced by my developing ideas. 
A coherent theoretical idea started developing during the coding, memoing and diagramming process. As my understanding developed, I went back to the data to look at specific, theoretically relevant instances. I then used these instances to further develop my theoretical model until the analysis of new instances no longer provided new insights [Strauss and Corbin, (1998), ch.10, p.13]. Thus, I ultimately arrived at the model presented below.

\subsection{Ensuring trustworthiness}

In addition to strict accuracy in data collection and analysis, I took additional means to ensure trustworthiness (Shah and Corley, 2006) of my study. First, I asked the CIO and his colleagues to comment on the earlier versions of this paper, which ensures that the data I am using accurately describe the events as perceived by the people investigated. Second, I presented my findings to several audiences and asked for their feedback. This helped me to refine the internal logic and analytical generalisability (and face validity) of my findings.

\section{Findings}

I discovered that the $\mathrm{CIO}$ investigated in this study used a refined set of tactics to facilitate and trigger coordinated action (Figure 2). He first created adequate levels of understanding in the people who were to take part in the coordinated action and increased their faith in the idea and in their ability to implement the idea together. The use of these tactics resulted in 'action potential', which the CIO then turned into coordinated action by using specific triggering techniques. ${ }^{2}$ Below, I will go through each element of the model in detail, reflect it back to the literature on sense-making and sense-giving, and explain how the model and its components are analytically generalisable to other settings.

Figure 2 Sense-giving can facilitate and trigger coordinated action

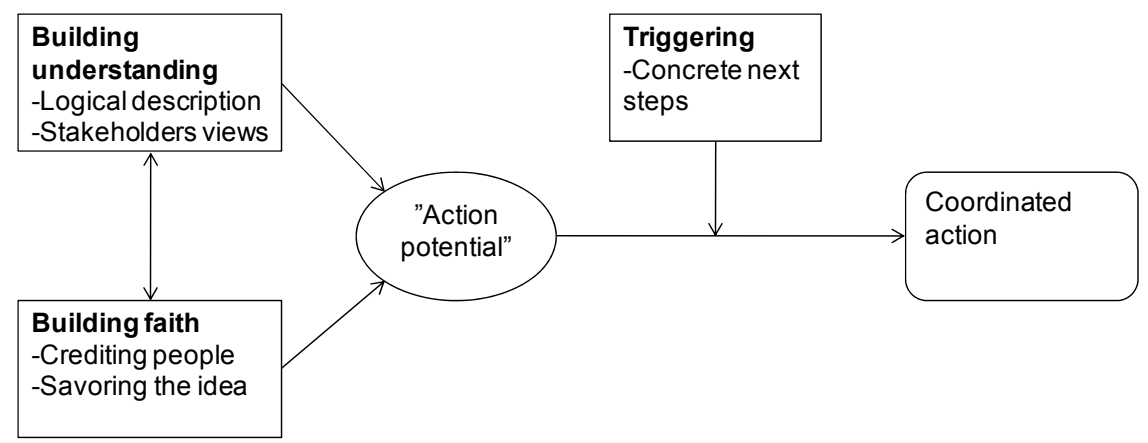

\section{$4.1 \quad$ Building understanding}

Understanding of a situation provides logical reasons why some things should be done and why they should be done in a certain way. The understanding, then, both motivates the actions to be taken and guides which kinds of actions are to be taken. Two key tactics of increasing understanding that that facilitates action were recognised. 


\title{
4.1.1 Logical description
}

The basic idea of this tactic is to describe the situation in a logical way, demonstrating how the proposed action would improve the situation. Components of the logical description include presenting how the current situation is a logical consequence of events that have taken place in other locations or in the past (cf. Brunninge, 2009) and how the proposed future action/goal would be the logical continuance of the development of things. As an example, the CIO described the conditions of the company and then logically deduced a preferred solution:

\begin{abstract}
"I think that, realistic for you, when one thinks us as a company, around the Baltic Sea and those others are small. A solution is needed where the near regions around Finland, and all of them are quite small ... Therefore, the [global] model won't suite us. Few users elsewhere. And our culture isn't mature enough, for example, English language is a problem. [continues the description and ultimate arrives at a conclusion that a certain way is to be preferred]." [Meeting: Re-calibrating collaboration with company Y]
\end{abstract}

The logical descriptions also often included synthesising fragmented information in a logical way as the meetings went on. This, together with the other logical rhetoric, made the organisational members view the $\mathrm{CIO}$ as a rational, task-focused, non-political person:

"Sometimes he blows the whistle after a long conversation and says that "have I understood it correctly that things are now like this and this, and if it is like that, doesn't it mean that we shall do like that' [...] He does not start politicking, but says things as they are and draws logical conclusions from that." [Interview transcript, sense-receiver speaking]

\subsubsection{Stakeholders' points of view}

Describing how different stakeholders view an issue and are likely to react to new actions constitutes the political component of the process of building understanding. The CIO often described how different people viewed an issue that was talked about and how the proponents of a new idea should therefore frame the issue.

"Person A and B and I were talking ... It seem to be a larger than life question to person A ... It wasn't about [logical reasons] but he just doesn't want to move because of comfort reasons. I don't want to annoy him, but we can't follow his desires like this. .. Therefore, say that we are only planning" ... "Let's talk about plan. To have everyone in the same [space]. First everyone will resist, and then notice that it is good."

These kinds of stakeholder-viewpoint-related descriptions further created understanding about the situation for the sense-receivers. Besides understanding the rational reasons why they should pursue certain goals, they also came to share political reasons why they should proceed in a certain way.

Having an adequately shared understanding of the basic logic of the situation - in terms of both rational goals and political means - increases the probability the different participants in the coordinated action are going to take consistent and mutually reinforcing action. This makes the development and implementation of new strategic initiatives more likely to succeed. 


\subsection{Building faith and trust}

Understanding what to do and how to do it is only one aspect of making coordinated action possible. Faith is also needed because "success depends on the energy of the act; energy depends on faith that we shall not fail" [Weick, (2006), p.1729]. I recognised that the CIO increased the participants' faith along two dimensions: he used 'savouring' to amplify the participants' faith in the idea itself; and he credited people who were to take part in the coordinated action to increase the participants' faith that the other members of the coordinated action would do their part.

\subsubsection{Savouring}

The sense-giver and other meeting participants often continued to discuss why the idea that was about to be implemented is good, even after they had decided to take action. For example, after they had decided to suggest a collaboration project to Firm X, they still continued to 'savour' the idea:

CIO: "[This will be good], yes, if we take the not the technology but the [core idea]."

Another participant: "So win/win, they get $[\ldots]$ and we get $[\ldots]$."

There was no rational reason to continue discussing the reasons for the idea because the goal of the meeting was to make a decision, and the decision had already been made. However, it would not be smart to argue that the savouring was time wasted. Instead, it further amplified the participants' faith in the goodness of idea, thus increasing the amount of energy they will put in the implementation of the idea. Savouring is therefore an important component of action-triggering sense-giving.

\subsubsection{Crediting people}

The second aspect of increasing faith relates to people who are to take part in the coordinated action. Because the success of an idea often depends on the actions of several people in a mutually reinforcing and complementary way (rather than just the sum of different participants' efforts), the effectiveness of a first person's action depends on the actions of the other persons. Therefore, the people need to believe that others will do their part well in order to have faith that their own, individual actions will lead to success. The CIO often achieved this effect by crediting the people who were to take part in the coordinated action:

\footnotetext{
"Start doing, I think it would be rather easy thing to do. They are really good people in [Firm Z] ... They did the [product] so that they just came to present a demo without us having asked ... If we did it with them, so that they would do it [in a similar way]."
}

The key aspect of crediting people was therefore showing and describing in concrete terms that the people who were to be participants in the coordinated action were both competent and motivated. 


\subsection{Triggering concrete action}

The first two main tactics - building understanding and building faith - make people more likely to take part in, put effort into, and succeed at coordinated actions. However, this likeliness can be viewed only as the potential to act, as faith and understanding of a situation do not induce people to take concrete steps. As the CIO explained:

\footnotetext{
"This is the typical way for me [being explicit about next steps]. I look at the time and bring up the next steps. This way we can get things organized. What is going to be done and by who. ... That someone takes the ball. Otherwise it could happen that it all remains only at the level of thoughts. 'Let's get back to it', and then nothing happens." [Interview with the CIO]
}

This triggering of coordinated action thus brings us back to the essence of sense-making. Only actions make things move forward: "it is what they do, not what they plan, that explains their success" [Weick, (1995), p.55]. These actions are often "micro-level actions. They are small actions, but they are small actions with large consequences" [Weick et al., (2005), p.419].

\section{Discussion}

I started this paper by asking how executives can create a fertile ground for novel, collective, and coordinated action. I recognised that to act as a collective, a group must have some level of shared understanding, trust and faith. Then, I noted that research on sense-making has recognised the importance of initial interpretations because they can become self-fulfilling prophesies; I also noted that research on sense-giving offers some methods for influencing these interpretations. However, no model that would describe how executives can really do it had been recognised. Thus, I focused my research on developing such a model.

I found that a sense-giver, who wants to create optimal starting conditions for coordinated action, should increase the 'action potential' of the group by building shared understanding and mutual faith and trust. Shared understanding can be created by describing the situation and goal logically and by describing different stakeholders' points of views and goals. Mutual faith and trust can be created by savouring the idea and by crediting the different members of the group. The consequent action potential can then be turned into action by using specific triggering tactics, such as setting clear goals.

This paper contributes to research on strategy implementation and sense-giving. To my knowledge, no prior study has investigated the process of creating a fertile ground for novel, coordinated action (i.e., for new strategy execution). Instead, the vast majority of sense-giving studies have focused on making the strategy accepted, in a cognitive sense (e.g., Hutzschenreuter and Kleindienst, 2006; Weick et al., 2005). Thus, the focus has been on whether people think that the new strategy is good or not, not on whether people actually do the strategy collectively, as a result of sense-giving. As I shift focus from this 'thinking' to 'doing', I extend research on sense-giving and strategy implementation.

The focus on implementation brings up new themes for discussion in strategy meetings that seem irrelevant from the point of view of mere acceptance. For example, building faith through savouring, after the idea has already been accepted, makes no 
sense from the rational-cognitive point of view. However, when we understand that acceptance is not enough but that also actions matter, we can see how the savouring increases the probability of effortful action. Similar points apply for the other tactics as well - understanding others' mental models and motives becomes necessary only when we understand that situations evolve as people start acting, and they then need to be able to predict what others will do to coordinate their actions; and the trust in others matters most because it indirectly influences the focal person's motivation to act and keep on acting.

As this paper presents only preliminary findings from a work in progress, several significant limitations should be mentioned. Regarding the theoretical grounding of this study, I have left the research on strategy-as-practice outside the presentation of this study. However, this stream must have a lot to contribute to the themes discussed in this paper. Secondly, my empirical material is relatively narrow, focusing only on one sense-giver. From the perspective that data provides inspiration for theory building (Siggelkow, 2007; Vuori, 2009), this is not a problem, as only the logic and face validity of the conceptual argument should matter. However, richer observations and comparative studies might offer more insights and confidence in the workings of different tactics (e.g., if we could compare several managers who use different tactics and combinations, we could extract the most effective and efficient sense-giving tactics by using empirical rather than theoretical justifications).

To conclude, I described how a sense-giver can create a fertile ground for novel, collective, coordinated action. My findings are preliminary and offer ample opportunities for future research.

\section{Acknowledgements}

This research has been supported by the Foundation of Economic Education (Grant Number 30310). The paper was originally developed as an assignment in Mike Manning's course on qualitative methods at Helsinki University of Technology. The paper was further developed in the Arctic Workshop at Espoo on 12-13 November 2009. The author would like to thank Mike and all the participants of the course and workshop for providing valuable support and feedback. The biggest thanks go to the CIO who allowed the author to observe his sense-giving tactics.

\section{References}

Balogun, J. and Johnson, G. (2004) 'Organizational restructuring and middle manager sensemaking', Academy of Management Journal, Vol. 47, No. 4, pp.523-549.

Balogun, J. and Johnson, G. (2005) 'From intended strategies to unintended outcomes: the impact of change recipient sensemaking', Organization Studies, Vol. 26, No. 11, pp.1573-1601.

Boudes, T. and Laroche, H. (2009) 'Taking off the heat: narrative sensemaking in post-crisis inquiry reports', Organization Studies, Vol. 30, No. 4, pp.377-396.

Brown, A.D., Stacey, P. and Nandhakumar, J. (2008) 'Making sense of sensemaking narratives', Human Relations, Vol. 61, No. 8, pp.1035-1062.

Brunninge, O. (2009) 'Using history in organizations: how managers make purposeful reference to history in strategy processes', Journal of Organizational Change Management, Vol. 22, No. 1, pp.8-26. 
Dirks, K.T. and Ferrin, D.L. (2001) 'The role of trust in organizational settings', Organization Science, Vol. 12, No. 4, pp.450-467.

Doz, Y.L. (1996) 'The evolution of cooperation in strategic alliances: initial conditions or learning processes?', Strategic Management Journal, Vol. 17.

Dunford, R. and Jones, D. (2000) 'Narrative in strategic change', Human Relations, Vol. 53, No. 9, pp.1207-1226.

Faraj, S. and Sproull, L. (2000) 'Coordinating expertise in software development teams', Management Science, pp.1554-1568.

Fiss, P.C. and Zajac, E.J. (2006) 'The symbolic management of strategic change: sensegiving via framing and decoupling', Academy of Management Journal, Vol. 49, No. 6, pp.1173-1193.

Foldy, E.G., Goldman, L. and Ospina, S. (2008) 'Sensegiving and the role of cognitive shifts in the work of leadership', Leadership Quarterly, Vol. 19, No. 5, pp.514-529.

Gioia, D.A. and Chittipeddi, K. (1991) 'Sensemaking and sensegiving in strategic change initiation’, Strategic Management Journal, Vol. 12, No. 6, pp.433-448.

Gioia, D.A. and Thomas, J.B. (1996) 'Identity, image, and issue interpretation: sensemaking during strategic change in academia', Administrative Science Quarterly, Vol. 41, No. 3, pp.370-403.

Gode-Sanchez, C. (2009) 'Coordination in volatile environments: how do fighter pilots 'strategizing' through their coordination practices?', EGOS Colloquium, Barcelona, Spain.

Hargadon, A.B. and Bechky, B.A. (2006) 'When collections of creatives become creative collectives: a field study of problem solving at work', Organization Science, Vol. 17, No. 4, pp.484-500

Hill, R.C. and Levenhagen, M. (1995) 'Metaphors and mental models - sensemaking and sensegiving in innovative and entrepreneurial activities', Journal of Management, Vol. 21, No. 6, pp.1057-1074.

Huber, G.P. and Lewis, K. (2010) 'Cross understanding: implications for group cognition and performance', Academy of Management Review, Vol. 35, No. 1, in press.

Hutzschenreuter, T. and Kleindienst, I. (2006) 'Strategy-process research: what have we learned and what is still to be explored', Journal of Management, Vol. 32, No. 5, pp.673-720.

Jarzabkowski, P. (2008) 'Shaping strategy as structuration process', Academy of Management Journal, Vol. 51, No. 4, pp.621-650.

Johnson, G., Melin, L. and Whittington, R. (2003) 'Micro strategy and strategizing: towards an activity-based view - guest editors' introduction', Journal of Management Studies, Vol. 40, No. 1, pp.3-22.

Kaplan, S. (2008) 'Framing contests: strategy making under uncertainty', Organization Science, Vol. 19, No. 5, pp.729-752.

Lee, T.W., Mitchell, T.R. and Sablynski, C.J. (1999) 'Qualitative research in organizational and vocational psychology, 1979-1999', Journal of Vocational Behavior, Vol. 55, No. 2, pp.161-187.

Livingston, S. (2003/1969) 'Pygmalion in management', Harvard Business Review, Vol. 81, No. 1, pp.97-106.

Maitlis, S. (2005) 'The social processes of organizational sensemaking', Academy of Management Journal, Vol. 48, No. 1, pp.21-49.

Maitlis, S. and Lawrence, T.B. (2007) 'Triggers and enablers of sensegiving in organizations', Academy of Management Journal, Vol. 50, No. 1, pp.57-84.

March, J.G. and Simon, H.A. (1958/1993) Organizations, 2nd ed., Wiley, New York.

Montague, R. (2006) Your Brain is (Almost) Perfect: How We Make Decisions, Plume/Penguin Group, New York, NY. 
Nag, R., Corley, K.G. and Gioia, D.A. (2007) 'The intersection of organizational identity, knowledge, and practice: attempting strategic change via knowledge grafting', Academy of Management Journal, Vol. 50, No. 4, pp.821-847.

Pratt, M.G. (2000) 'The good, the bad, and the ambivalent: managing identification among Amway distributors', Administrative Science Quarterly, Vol. 45, No. 3, pp.456-493.

Quinn, R.W. and Worline, M.C. (2008) 'Enabling courageous collective action: conversations from United Airlines Flight 93', Organization Science, Vol. 19, No. 4, pp.497-516.

Rico, R., Sanchez-Manzanares, M., Gil, F. and Gibson, C. (2008) 'Team implicit coordination processes: a team knowledge-based approach', Academy of Management Review, Vol. 33, No. 1, pp.163-184.

Rosen, M. (1988) 'You asked for it: Christmas at the bosses'expense [1]', Journal of Management Studies, Vol. 25, No. 5, pp.463-480.

Rouleau, L. (2005) 'Micro-practices of strategic sensemaking and sensegiving: how middle managers interpret and sell change every day', Journal of Management Studies, Vol. 42, No. 7, pp.1413-1441.

Senge, P. (1990) The Fifth Discipline, Currency Doubleday, New York.

Shah, S. and Corley, K. (2006) 'Building better theory by bridging the quantitative-qualitative divide', Journal of Management Studies, Vol. 43, No. 8, pp.1821-1835.

Siggelkow, N. (2007) 'Persuasion with case studies', Academy of Management Journal, Vol. 50, No. 1, pp.20-24.

Sonenshein, S. (2006) 'Crafting social issues at work', Academy of Management Journal, Vol. 49, No. 6, pp.1158-1172.

Spender, J.C. (1996) 'Making knowledge the basis of a dynamic theory of the firm', Strategic Management Journal, Vol. 17, pp.45-62.

Steuer, R. and Wood, T. (2008) 'Storytellers and their discursive strategies in a post-acquisition process', Journal of Organizational Change Management, Vol. 21, No. 5, pp.574-588.

Strauss, A.L. and Corbin, J. (1998) Basics of Qualitative Research: Techniques and Procedures for Developing Grounded Theory, 2nd ed., Sage.

Thompson, J. (1967) Organizations in Action: Social Science Bases of Administrative Theory, McGraw-Hill, New York.

Tierney, P. and Farmer, S.M. (2004) 'The Pygmalion process and employee creativity', Journal of Management, Vol. 30, No. 3, pp.413-432.

Vroom, V.H. (1964) Work and Motivation, Wiley, New York.

Vuori, T. (2009) 'What can we learn about theory building from Stephen King?', Academy of Management Annual Meeting, Chicago.

Weick, K.E. (1979) The Social Psychology of Organizing, 2nd ed., Addison Wesley, MA.

Weick, K.E. (1988) 'Enacted sensemaking in crisis situations', Journal of Management Studies, Vol. 25, No. 4, pp.305-317.

Weick, K.E. (1993) 'The collapse of sensemaking in organizations - the Mann Gulch disaster', Administrative Science Quarterly, Vol. 38, No. 4, pp.628-652.

Weick, K.E. (1995) Sensemaking in Organizations, Sage Publications, Thousand Oaks, CA.

Weick, K.E. (2006) 'Faith, evidence, and action: better guesses in an unknowable world', Organization Studies, Vol. 27, No. 11, pp.1723-1736.

Weick, K.E. and Roberts, K.H. (1993) 'Collective mind in organizations - heedful interrelating on flight decks', Administrative Science Quarterly, Vol. 38, No. 3, pp.357-381.

Weick, K.E., Sutcliffe, K.M. and Obstfeld, D. (2005) 'Organizing and the process of sensemaking', Organization Science, Vol. 16, No. 4, pp.409-421. 


\section{Notes}

1 I have structured the theoretical background in a way that is consistent with my empirical findings in order to make the paper more readable. However, the reader should understand that this way of structuring the literature only emerged after I had developed my findings. (An alternative structure would be general review on all related topics, but this would make the paper harder to follow) As usual in qualitative research, the findings emerged abductively and iteratively, wherein I move back and forth between literature, data, and my own theorising. [see, e.g., Gioia and Chittipeddi (1991: footnote 1 on p.434) for additional justification for my approach].

2 Note that my empirical evidence does not include the actual actions that followed. I observed only the process through which the sense-giver created the 'action potential'. The claim that coordinated action resulted (or that its chances of success increased) because of the sense-giving tactics is based on conceptual reasoning. 